\title{
(6) OPEN ACCESS \\ A community-based multilevel intervention for smoking, physical activity and diet: short-term findings from the Community Interventions for Health programme in Hangzhou, China
}

\author{
Jun Lv, ${ }^{1}$ Qing-Min Liu, ${ }^{2}$ Yan-Jun Ren, ${ }^{2}$ Ping-Ping He, ${ }^{1}$ Sheng-Feng Wang, ${ }^{1}$ \\ Fang Gao, ${ }^{1} \mathrm{Li}$-Ming $\mathrm{Li}^{1}{ }^{1}$ on behalf of the Community Interventions for \\ Health $(\mathrm{ClH})$ collaboration
}

${ }^{1}$ Department of Epidemiology and Biostatistics, School of Public Health, Peking University Health Science Center, Beijing, China ${ }^{2}$ Division for Chronic and NonCommunicable Disease Contro and Prevention, Hangzhou Center for Disease Control and Prevention, Hangzhou, China

\section{Correspondence to} Li-Ming Li, Department of Epidemiology and Biostatistics, School of Public Health, Peking University Health Science Center, 38 Xueyuan Road, Beijing, 100191, China; Imlee@vip.163.com

Received 10 September 2013 Revised 1 November 2013 Accepted 12 November 2013 Published Online First 2 December 2013

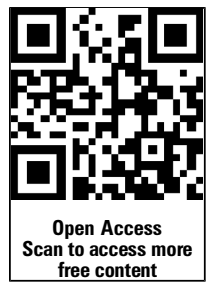

\section{ABSTRACT}

Background To assess the short-term impact of a comprehensive, community-based multilevel intervention on knowledge, beliefs and practices with respect to smoking, physical activity and diet in Hangzhou, China. Methods A non-randomised, controlled, before-after quasi-experimental trial was conducted in two intervention areas and one comparison area. The intervention built on a socioecological framework and took place across four settings: neighbourhoods, schools, workplaces and community health centres. Two independent cross-sectional surveys of adults aged 18-64 years at baseline and a subsequent follow-up were conducted in 2008/2009 and 2011 in the intervention and comparison areas. A 2-year intervention programme was begun in mid-2009 and continued until mid-2011.

Results A total of 2016 adults at baseline and 2016 adults at follow-up completed the survey. Over the 2-year intervention period, the intervention areas showed a statistically significant decline ( $25.2 \%$ vs $18.7 \%$, $p<0.001)$ in the prevalence of smoking compared with the comparison area $(18.0 \%$ vs $16.4 \%, p=0.343)$. The proportion of individuals who had noticed anyone smoking in any of nine locations in the previous 30 days demonstrated a statistically significant decline in the intervention $(78.9 \%$ vs $66.5 \%, p<0.001)$ and comparison $(76.3 \%$ vs $66.5 \%, p<0.001)$ areas. The fruit and vegetable consumption score increased in a statistically significant manner in the intervention (24.84 vs $25.97, \mathrm{p}=0.036$ ) and comparison ( 24.25 vs 26.67 , $p<0.001)$ areas. The metabolic equivalent of physical activity increased from 1204 to $1386(p=0.023)$ in the intervention areas compared with 918 to 924 in the comparison area $(p=0.201)$.

Conclusions After a 2-year intervention, beneficial changes were noted in the intervention areas with respect to smoking and physical activity but not diet. A community-based multilevel intervention programme is feasible in urban China.

\section{BACKGROUND}

China is undergoing a rapid rise in the burden of non-communicable diseases (NCDs). ${ }^{1-3}$ One of the major forces is the rapid increase in high-risk lifestyle behaviours such as smoking, unhealthy diet and insufficient physical activity (PA). ${ }^{3}$ Since the early 1970s, a number of community-based intervention (CBI) programmes have sought to promote risk-reducing lifestyle changes in several industrialised countries. ${ }^{4}$ These programmes emphasise the fact that merely providing riskreduction measures for clinically high-risk individuals in health service settings has only a limited impact on the entire country. By contrast, if the population as a whole was targeted, even modest changes to risk factors and a heart-healthy lifestyle would potentially generate a huge public health impact. ${ }^{5}$ Many researchers are increasingly interested in developing, implementing and evaluating multilevel intervention based on socioecological models ${ }^{6-9}$ which are believed to be most likely to achieve substantial and sustained change.

Although there is sufficient knowledge about 'what should be done' to address the leading NCDs and their underlying risk factors, the key question at present is how can our existing knowledge of NCDs best be applied to effective prevention in real-life situations in different social and cultural environments and their particular political and organisational systems? ${ }^{5}$ Rather than proceeding with a large-scale effectiveness test in a developing country with limited resources, a more appropriate research initiative would be to adapt a 'proven' intervention to new settings and determine its impact on significant outcomes. ${ }^{10}$ Additionally, although numerous CBI programmes have been undertaken, there is a clear need for well-designed evaluations of combined community interventions, especially in developing contries. ${ }^{11} 12$

Community Interventions for Health $(\mathrm{CIH})$ is a multinational collaboration programme of the Oxford Health Alliance that took place in China, India and Mexico during its pilot phase (2008-2012). CIH relies on comprehensive community-based multilevel interventions to improve knowledge, beliefs and practices regarding smoking, PA and diet. ${ }^{13} \mathrm{CIH}$ seeks to identify effective, feasible and culturally acceptable strategies for implementation in each site. In contrast to traditional epidemiological designs, which generally focus exclusively on cause and effect, $\mathrm{CIH}$ is designed as an action-oriented research project with an extensive evaluation component that is intended to promote replication.

The Chinese site for $\mathrm{CIH}$ during the pilot phase was located in Hangzhou city. This article sought 
to assess whether more favourable changes occurred in knowledge, beliefs and practices with respect to smoking, PA and diet in the intervention areas compared with the comparison area in Hangzhou. The primary hypotheses in this analysis are that exposure to multilevel intervention would (1) decrease the prevalence of current smoking and the average exposure to secondhand smoke; (2) increase the average consumption of healthy fruits and vegetables (FVs); and (3) increase PA levels.

\section{METHODS}

The study design and rationale for the intervention and evaluation methods that were employed in the $\mathrm{CIH}$ programme have been described elsewhere. ${ }^{13}$ Briefly, a comprehensive CBI trial to improve knowledge, beliefs and practices with respect to smoking, PA and diet was conducted using a non-randomised, controlled, before-after quasi-experimental evaluation design. Three adjacent districts located in a central geographical location of Hangzhou were included in the CIH programme. ${ }^{14}$ Xiacheng district and Gongshu district were selected as the intervention areas. Xihu district served as the comparison area. Informed consent ensuring privacy and confidentiality was obtained from the participants.

\section{Interventions}

A 2-year intervention programme was begun in mid-2009 in the intervention areas and continued until mid-2011. Four primary intervention strategies were employed in the $\mathrm{CIH}$ programme: community mobilisation, structural change, health education and social marketing. To reach individuals where they lived, worked, learned and received care, the interventions occurred across four settings, including neighbourhoods, schools, workplaces and community health centres. ${ }^{13}$ The International Evaluation Study Coordination Centre summarised evidencebased practices based on an extensive literature review and provided guidance for implementing and adapting interventions across all country sites and settings. We reviewed the baseline findings regarding this topic and tailored the interventions to the specific needs and priorities of Hangzhou. For example, the baseline findings indicated that high-risk lifestyle profiles were more prevalent among people in the $40-49$ years age group. ${ }^{14}$ Therefore workplace health intervention offered several advantages in that a substantial number of the working population can be reached and multiple levels of influence on behaviour can be targeted. Meanwhile school-based interventions for health could also provide opportunities to increase positive influences of children on their middle-aged parents.

The socioecological model was used as a framework for developing multilevel intervention (table 1). The intervention activities were implemented mainly by local staff of the district Centres for Disease Control and Prevention, doctors of community health centres, community public health assistants, school doctors and worksite clinic doctors. Xihu district, as the comparison area, followed routine practices for NCD prevention and control and received no intervention activities that were specific to the $\mathrm{CIH}$ programme. Routine practices typically include distributing messages related to healthy lifestyles and NCDs through various community-based channels on a small scale, providing free screening and medical consultation for major NCDs, holding community-wide events on special days, implementing and enforcing smoking bans and restrictions and training health professionals.

\section{Evaluation design}

The short-term impact evaluation was conducted through two independent surveys of cross-sectional samples in the intervention and comparison areas. We conducted the baseline survey in Hangzhou from October 2008 to August 2009, which was before the start of the intervention. We conducted the follow-up survey from June 2011 to February 2012, which was after the 2-year intervention. Although the baseline and follow-up surveys did not happen exactly at the same time of the year, both of them went through seasons with similar weather conditions. The baseline and follow-up surveys were independent and equal in size. The same sampling design was used for the baseline and follow-up surveys. ${ }^{14}$ The eligible subjects were individuals aged 18-64 years who had lived in the local district for at least 1 year. A simple random sample of households was taken from the lists of community households of three districts. One of the eligible persons in the sampled households was identified to finish a questionnaire survey using the Kish method, which is based on a full listing of all eligible persons in the household by age and gender. ${ }^{15}$ All interviewers were asked to have a maximum of three door-to-door visiting attempts per sampled household, including three different days and at least one night attempt. Face-to-face interviews were conducted by trained interviewers.

\section{Measures and variables}

The core development team of $\mathrm{CIH}$ designed the surveys based on a review of existing reliable surveys. ${ }^{13}$ Basic

Table 1 Brief descriptions of the multilevel interventions based on the socioecological model of health

\begin{tabular}{|c|c|}
\hline Level & Practical applications-examples from $\mathrm{CIH}$ \\
\hline Individual (intrapersonal) & $\begin{array}{l}\text { Distributing health-related messages through } \\
\text { various channels; } \\
\text { Distributing tools for a healthy lifestyle including } \\
\text { salt spoons and oil pots; } \\
\text { Providing free disease screening and risk } \\
\text { assessment for cardiovascular disease; } \\
\text { Providing physical fitness testing; }\end{array}$ \\
\hline $\begin{array}{l}\text { Social environment } \\
\text { (interpersonal) }\end{array}$ & $\begin{array}{l}\text { Encouraging health professionals to screen and } \\
\text { give prescription for health; } \\
\text { Starting a walking club; } \\
\text { Increasing positive interaction between parents } \\
\text { and children to promote healthy lifestyle; }\end{array}$ \\
\hline Physical environment & $\begin{array}{l}\text { Implementing a smoke-free worksite initiative; } \\
\text { Implementing and enforcing smoking bans and } \\
\text { restrictions in public areas; } \\
\text { Using point-of-decision prompts to increase stair } \\
\text { use; } \\
\text { Organising work-break exercises, sports } \\
\text { competitions, mountain-climbing events and } \\
\text { sports interest groups; } \\
\text { Building walking trails with stone distance } \\
\text { markers along the canal and in the community } \\
\text { park; } \\
\text { Building health theme parks; } \\
\text { Initiation of a public bicycle service system; } \\
\text { Healthy cooking intervention in restaurants and } \\
\text { workplace cafeteria; } \\
\text { Making health-related or calorie information of } \\
\text { foods available to consumers; }\end{array}$ \\
\hline Policy environment & $\begin{array}{l}\text { Smoke control ordinance in public places of } \\
\text { Hangzhou; } \\
\text { Policy and planning for healthy city movement } \\
\text { and enhancing public transportation. }\end{array}$ \\
\hline
\end{tabular}


sociodemographic information was collected from all of the participants, including age, sex, education and household assets. The definitions and grouping method for this information have been described elsewhere. ${ }^{14}$ Self-reported engagement in any intervention activities was included in the follow-up survey and analysed in this article.

Responses to questions that addressed knowledge, attitudes and behaviour in relation to lifestyle issues were scored. The rules for the score calculation are shown in table 2 . The consumption frequency score for eating vegetables (or fruit) was multiplied by the score for the serving size, and the total of the two derived scores generated a summary score for FV consumption. Current smoking status of manufactured cigarettes and secondhand smoke (SHS) in a typical day were asked. Subjects were also asked to select locations where they had seen anyone smoking inside in the past 30 days. The scores for the individual locations were added to produce a summary score.
PA was assessed with questions from the short form of the International Physical Activity Questionnaire (IPAQ), which has reasonable measurement properties for monitoring population levels of PA among 18-65-year-old adults in diverse settings ${ }^{16}$ and can be used internationally to obtain comparable estimates of PA. The IPAQ assesses PA undertaken across a comprehensive set of domains including (1) leisure time PA; (2) domestic and gardening activities; (3) work-related PA; (4) transport-related PA. The IPAQ short form asks about three specific types of activity undertaken in the four domains mentioned above, that is, walking, moderate-intensity activities and vigorous-intensity activities. Following the IPAQ scoring protocol, ${ }^{17}$ we yielded a combined total score in metabolic equivalent of physical activity (MET)-minutes per week for all of the walking, moderate PAs and vigorous PAs that had occurred during the previous 7 days. We precisely followed the recommended categorical scoring system $^{17}$ to create three levels of PA: low, moderate and high. ${ }^{14}$

Table 2 The calculated scores for knowledge, beliefs and behaviours with respect to lifestyle issues

\begin{tabular}{|c|c|c|c|}
\hline & Question & Score & Scoring criteria \\
\hline \multicolumn{4}{|l|}{ Knowledge and beliefs } \\
\hline \multicolumn{2}{|l|}{ Health hazards of tobacco } & \multicolumn{2}{|l|}{$0-10$} \\
\hline Smoking tobacco & $\begin{array}{l}\text { Stroke } \\
\text { Lung cancer } \\
\text { Heart attack } \\
\text { Cataracts } \\
\text { Miscarriage } \\
\text { Low birthweight babies }\end{array}$ & $\begin{array}{l}0-1 \\
0-1 \\
0-1 \\
0-1 \\
0-1 \\
0-1\end{array}$ & $\begin{array}{l}\text { Yes }=1 \\
\text { No }=0 \\
\text { Don't know/not sure }=0\end{array}$ \\
\hline Exposure to secondhand smoke & $\begin{array}{l}\text { Lung cancer in adults } \\
\text { Heart disease in adults } \\
\text { Lung problems in children } \\
\text { Sudden infant death syndrome }\end{array}$ & $\begin{array}{l}0-1 \\
0-1 \\
0-1 \\
0-1\end{array}$ & \\
\hline Impact of diet on health & $\begin{array}{l}\text { Heart disease } \\
\text { Diabetes } \\
\text { Cancer }\end{array}$ & $\begin{array}{l}0-3 \\
0-1 \\
0-1 \\
0-1\end{array}$ & $\begin{array}{l}\text { Yes }=1 \\
\text { No=0 } \\
\text { Don't know/not sure }=0\end{array}$ \\
\hline Benefits of regular physical activity & $\begin{array}{l}\text { Feel less depressed and/or bored } \\
\text { Lose weight } \\
\text { Feel less tension and stress } \\
\text { Improve your health or reduce your risk of disease } \\
\text { Do better on your job } \\
\text { Improve your heart and lung fitness } \\
\text { Gain muscle }\end{array}$ & $\begin{array}{l}0-7 \\
0-1 \\
0-1 \\
0-1 \\
0-1 \\
0-1 \\
0-1 \\
0-1\end{array}$ & $\begin{array}{l}\text { Strongly agree }=1 \\
\text { Somewhat agree }=1 \\
\text { Neither agree nor disagree }=0 \\
\text { Somewhat disagree }=0 \\
\text { Strongly disagree }=0 \\
\text { Don't know/not sure }=0\end{array}$ \\
\hline \multicolumn{4}{|l|}{ Lifestyle behaviours } \\
\hline \multicolumn{2}{|c|}{ FV consumption (Fruit $C_{\text {freq } \times a d e q}+$ Vegetable $C_{\text {freq } \times a d e q}$ ) } & $0-56$ & \\
\hline Frequency of FV consumption & $\begin{array}{l}\text { Fruit } \\
\text { Vegetable }\end{array}$ & $\begin{array}{l}0-7 \\
0-7\end{array}$ & $\begin{array}{l}\text { Eating days per week: } \\
<1 \text { day/week }=0 \\
1-7 \text { day/week }=1-7\end{array}$ \\
\hline Adequacy of FV consumption & $\begin{array}{l}\text { Fruit } \\
\text { Vegetable }\end{array}$ & $\begin{array}{l}0-4 \\
0-4\end{array}$ & $\begin{array}{l}\text { Servings per day: } \\
\text { I don't eat }=0 \\
1-4 \text { servings }=1-4 \\
5 \text { or more servings }=4\end{array}$ \\
\hline \multicolumn{4}{|l|}{ Potential environmental tobacco smoke } \\
\hline Having seen anyone smoking & $\begin{array}{l}\text { Home } \\
\text { Friend's home } \\
\text { Workplace } \\
\text { Private office building } \\
\text { School } \\
\text { Health centre } \\
\text { Restaurant } \\
\text { Government building } \\
\text { Public transportation }\end{array}$ & $\begin{array}{l}0-9 \\
0-1 \\
0-1 \\
0-1 \\
0-1 \\
0-1 \\
0-1 \\
0-1 \\
0-1 \\
0-1\end{array}$ & $\begin{array}{l}\text { Yes }=1 \\
\text { No=0 } \\
\text { Don't know/not sure }=0\end{array}$ \\
\hline
\end{tabular}

FV, fruit and vegetable. 


\section{Statistical analyses}

We used Stata/MP V.12.1 for Windows (StataCorp LP, Texas, USA) for analysis. ${ }^{18}$ Design-based approach was used to analyse this complex survey data, which involved district-based stratification and unequal sampling probabilities among three districts. The module specific for survey data analysis in Stata was employed. The sampling weights were calculated by taking the inverse of the sampling fraction in each of three districts at baseline and follow-up. Stata lacks non-parametric procedures for complex survey data. We then replaced the variable which was interval but not normally distributed (ie, PA score in MET-minutes per week) with their ranks, then applied the usual parametric methods. The ordered logistic regression for survey data was used to compare differences between two independent groups if the dependent variable was ordinal.

\section{RESULTS}

A total of 2016 adults at baseline and 2016 adults at follow-up completed the survey, including 1016 adults from the intervention areas and 1000 from the comparison area. Table 3 presents the general characteristics of the study participants. There were no significant differences in sociodemographic characteristics between baseline and follow-up surveys in the intervention areas, and also in the comparison area except for older age at follow-up in the comparison area. Relative to the individuals in the comparison area, the individuals in the intervention areas demonstrated a higher mean age at baseline, a lower education level and a lower socioeconomic status; in addition, in the intervention areas there was a lower proportion of household-owned cars than in the comparison area.

Table 4 indicates self-reported engagement in any intervention activities during the 12 months prior to the follow-up survey. More people in the intervention areas $(87.8 \%)$ than in the comparison area $(78.6 \%)$ saw or participated in the mentioned events or activities. Higher proportions of self-reported engagement were found in the intervention areas than in the comparison area in 11 out of the 12 intervention activities. More than $40 \%$ of the participants in the intervention areas reported that they had ridden a public bicycle (47.1\%), noticed a point-of-decision prompt encouraging the use of stairs (46.9\%), seen a form of health information material (43.9\%), or observed one of the distance marker or health signs installed on the footpath (41.4\%). The three most significant differences in the engagement of intervention activities were with respect to observing distance markers and health signs (41.4\% vs $23.1 \%$ ), noticing point-of-decision prompts encouraging the use of stairs (46.9\% vs $29.3 \%$ ), and receiving tools to promote the control of salt, oil and weight (37.9\% vs $20.6 \%$ ).

Table 5 indicates the results for knowledge, beliefs and practices with respect to three major lifestyle factors in the intervention and control areas for the baseline and follow-up surveys. Over the 2-year intervention period, tobacco-related knowledge and beliefs improved in the intervention and comparison areas. The improvements were significantly larger in the comparison area (mean score from 5.21 to 6.38) than in the intervention areas (mean score from 4.97 to 5.74 ). The score for diet-related knowledge and belief declined from 1.98 to 1.68 in the intervention areas and did not change in the comparison area. The score for PA-related knowledge and belief declined slightly in the intervention (from 5.38 to 5.04) but not in the comparison area.

FV consumption increased in the intervention areas (mean score from 24.8 to 26.0 ) and the comparison area (mean score from 24.3 to 26.7). The metabolic equivalent of PA and the proportion of IPAQ categories indicated a higher level of PA in the intervention areas compared with the comparison area. The level of PA (MET-min/week) increased from 1204 to 1386 in the intervention areas after the 2-year intervention.

The prevalence of current cigarette smoking at baseline was higher in the intervention areas (25.2\%) than in the comparison area $(18.0 \%)$. The intervention areas showed a statistically significant decline of $25.8 \%$ (from $25.2 \%$ to $18.7 \%$ ) in the prevalence of smoking during the follow-up. The prevalence of smoking among women was very low. The prevalence of smoking among men also demonstrated a statistically significant reduction in the intervention areas, from $48.7 \%$ to $38.7 \%$. The

Table 3 The general characteristics of the study participants in the intervention and comparison areas according to the baseline and follow-up surveys

\begin{tabular}{|c|c|c|c|c|c|c|c|c|}
\hline & \multicolumn{3}{|c|}{ Intervention areas (I) } & \multicolumn{3}{|c|}{ Comparison area (C) } & \multicolumn{2}{|c|}{$p$ Value for I versus $C$} \\
\hline & Baseline & Follow-up & $p$ Value & Baseline & Follow-up & $p$ Value & Baseline & Follow-up \\
\hline $\mathrm{n}$ & 1016 & 1016 & - & 1000 & 1000 & - & - & - \\
\hline Males, n (\%) & $503(49.5)$ & $473(46.6)$ & 0.183 & $474(47.4)$ & $446(44.6)$ & 0.209 & 0.344 & 0.378 \\
\hline Age (years), mean $\pm S D$ & $43.9 \pm 12.6$ & $44.1 \pm 12.2$ & 0.630 & $41.7 \pm 11.5$ & $43.7 \pm 12.3$ & $<0.001$ & $<0.001$ & 0.404 \\
\hline \multicolumn{9}{|l|}{ Age group, $\mathrm{n}(\%)$} \\
\hline $18-29$ & $177(17.4)$ & $165(16.2)$ & 0.650 & $155(15.5)$ & $149(14.9)$ & 0.002 & $<0.001$ & 0.059 \\
\hline $30-39$ & $185(18.2)$ & $190(18.7)$ & & $321(32.1)$ & $253(25.3)$ & & & \\
\hline $40-49$ & $273(26.9)$ & $274(27.0)$ & & $249(24.9)$ & $259(25.9)$ & & & \\
\hline $50-64$ & $381(37.5)$ & $387(38.1)$ & & $275(27.5)$ & $339(33.9)$ & & & \\
\hline \multicolumn{9}{|l|}{ Education, n (\%) } \\
\hline Junior high school or below & 337 (33.4) & $306(30.2)$ & 0.093 & $173(17.6)$ & $184(18.6)$ & 0.465 & $<0.001$ & $<0.001$ \\
\hline Senior high school & $267(26.4)$ & $268(26.4)$ & & $195(19.8)$ & $201(20.3)$ & & & \\
\hline College/university or postgraduate degree & $406(40.2)$ & $440(43.4)$ & & $617(62.6)$ & $605(61.1)$ & & & \\
\hline \multicolumn{9}{|l|}{ Asset index, n (\%) } \\
\hline Low & $478(47.1)$ & $500(49.5)$ & 0.473 & $357(36.2)$ & $377(38.2)$ & 0.234 & $<0.001$ & $<0.001$ \\
\hline Medium & $384(37.9)$ & $354(35.0)$ & & $373(37.8)$ & $377(38.2)$ & & & \\
\hline High & $152(15.0)$ & $157(15.5)$ & & $256(26.0)$ & $234(23.7)$ & & & \\
\hline Having car in household, $\mathrm{n}(\%)$ & $228(22.4)$ & $296(29.2)$ & $<0.001$ & 407 (41.1) & $494(49.9)$ & $<0.001$ & $<0.001$ & $<0.001$ \\
\hline
\end{tabular}


Table 4 Self-reported engagement in any intervention activities in the intervention and comparison areas in the 12 months prior to the follow-up survey (design-based analysis) $(\% \pm$ SE)

\begin{tabular}{|c|c|c|c|}
\hline & $\begin{array}{l}\text { Intervention } \\
\text { areas } \\
(\mathrm{N}=1014)\end{array}$ & $\begin{array}{l}\text { Comparison } \\
\text { area } \\
(\mathrm{N}=996)\end{array}$ & p Value \\
\hline Had seen any form of health information materials (eg, brochure, flyer, poster) made by local BOHs, CDCs and CHCs & $43.9 \pm 1.7$ & $35.7 \pm 1.5$ & $<0.001$ \\
\hline Had seen any point-of-decision prompt to increase stair use made by local BOH, CDCs and CHCs & $46.9 \pm 1.7$ & $29.3 \pm 1.4$ & $<0.001$ \\
\hline $\begin{array}{l}\text { Had received tools for promoting control of salt, oil and weight control including salt spoon, oil pot and BMI calculator } \\
\text { distributed by local BOHs, CDCs and CHCs }\end{array}$ & $37.9 \pm 1.7$ & $20.6 \pm 1.3$ & $<0.001$ \\
\hline Had attended public lectures on disease or healthy lifestyle organised by local CHCs & $22.2 \pm 1.5$ & $14.5 \pm 1.1$ & $<0.001$ \\
\hline Had attended community events in some special days, for example, World No Tobacco Day, World Diabetes Day, etc. & $15.1 \pm 1.3$ & $7.8 \pm 0.9$ & $<0.001$ \\
\hline Had joined a walkers' club which was organised by one of the local CHCs & $4.5 \pm 0.8$ & $2.7 \pm 0.5$ & 0.042 \\
\hline Your workplace had achieved a smoke-free workplace or worksite smoking control* & $36.3 \pm 2.1$ & $25.8 \pm 1.7$ & $<0.001$ \\
\hline The CHCs you had visited achieved smoke-free hospital & $24.4 \pm 1.5$ & $10.8 \pm 1.0$ & $<0.001$ \\
\hline The CHCs you had visited established quit smoking clinics or provided quit smoking services & $4.4 \pm 0.7$ & $2.7 \pm 0.5$ & 0.054 \\
\hline $\begin{array}{l}\text { Had received free blood pressure and glucose testing, established personal health record, learned your cardiovascular } \\
\text { disease } 10 \text {-year risk, or received guidance on the management of hypertension and diabetes from doctors in local CHCs }\end{array}$ & $34.2 \pm 1.6$ & $27.5 \pm 1.4$ & 0.002 \\
\hline $\begin{array}{l}\text { Had seen distance markers and health signs installed on either side of the footpath in the community, park or along } \\
\text { the canal }\end{array}$ & $41.4 \pm 1.7$ & $23.1 \pm 1.3$ & $<0.001$ \\
\hline Had ridden the public bicycle in Hangzhou & $47.1 \pm 1.7$ & $35.5 \pm 1.5$ & $<0.001$ \\
\hline I did not see or participate in any abovementioned events or activities & $12.2 \pm 1.1$ & $21.4 \pm 1.3$ & $<0.001$ \\
\hline
\end{tabular}

*The denominator was the number of people who had a job at follow-up survey.

$\mathrm{BOH}$, Bureau of Health, CDC, Centre for Disease Control; CHC, community health centre.

Table 5 Knowledge, beliefs and practices with respect to three major lifestyle issues in the intervention and control areas in the baseline and follow-up surveys (design-based analysis)*

\begin{tabular}{|c|c|c|c|c|c|c|c|c|}
\hline & \multicolumn{3}{|c|}{ Intervention areas (I) } & \multicolumn{3}{|c|}{ Comparison area (C) } & \multicolumn{2}{|c|}{$\begin{array}{l}p \text { Valuet for I } \\
\text { versus C }\end{array}$} \\
\hline & Baseline & Follow-up & p Value $\ddagger$ & Baseline & Follow-up & p Value $\ddagger$ & Baseline & Follow-up \\
\hline \multicolumn{9}{|l|}{ Knowledge and belief } \\
\hline Health hazards of tobacco, mean \pm SE & $5.0 \pm 0.1$ & $5.7 \pm 0.1$ & $<0.001$ & $5.2 \pm 0.1$ & $6.4 \pm 0.1$ & $<0.001$ & 0.115 & $<0.001$ \\
\hline Impact of diet on health, mean & $2.0 \pm 0.04$ & $1.7 \pm 0.05$ & $<0.001$ & $2.0 \pm 0.04$ & $2.1 \pm 0.04$ & 0.073 & 0.234 & $<0.001$ \\
\hline Benefits of regular physical activity, mean & $5.4 \pm 0.1$ & $5.0 \pm 0.1$ & 0.013 & $5.3 \pm 0.1$ & $5.0 \pm 0.1$ & 0.429 & 0.333 & 0.441 \\
\hline \multicolumn{9}{|l|}{ Lifestyle behaviours } \\
\hline Current smoking prevalence (\%) & $25.2 \pm 1.4$ & $18.7 \pm 1.3$ & $<0.001$ & $18.0 \pm 1.2$ & $16.4 \pm 1.2$ & 0.343 & $<0.001$ & 0.188 \\
\hline Among men (\%) & $48.7 \pm 2.3$ & $38.7 \pm 2.4$ & 0.003 & $36.9 \pm 2.2$ & $35.7 \pm 2.3$ & 0.708 & $<0.001$ & 0.374 \\
\hline Among women (\%) & $2.2 \pm 0.7$ & $1.5 \pm 0.6$ & 0.411 & $1.0 \pm 0.4$ & $0.9 \pm 0.4$ & 0.932 & 0.113 & 0.400 \\
\hline FV consumption, mean & $24.8 \pm 0.4$ & $26.0 \pm 0.4$ & 0.036 & $24.3 \pm 0.4$ & $26.7 \pm 0.4$ & $<0.001$ & 0.266 & 0.183 \\
\hline $\begin{array}{l}\text { Metabolic equivalent of physical activity } \\
\text { (MET-minutes/week), median }\left(\mathrm{P}_{25}, \mathrm{P}_{75}\right)\end{array}$ & $1204(495,2373)$ & $1386(693,2457)$ & 0.023 & $918(398,1836)$ & $924(438,1980)$ & 0.201 & $<0.001$ & $<0.001$ \\
\hline \multicolumn{9}{|l|}{ Proportion of IPAQ categories, \% } \\
\hline Low & $29.4 \pm 1.5$ & $25.2 \pm 1.5$ & 0.041 & $34.4 \pm 1.5$ & $32.5 \pm 1.5$ & 0.088 & 0.001 & $<0.001$ \\
\hline Moderate & $51.1 \pm 1.6$ & $53.2 \pm 1.7$ & & $51.4 \pm 1.6$ & $49.7 \pm 1.6$ & & & \\
\hline High & $19.4 \pm 1.3$ & $21.7 \pm 1.4$ & & $14.2 \pm 1.1$ & $17.8 \pm 1.2$ & & & \\
\hline \multicolumn{9}{|l|}{ Potential SHS } \\
\hline $\begin{array}{l}\text { Adults having noticed people smoking in any } \\
\text { of nine settings }(\%)\end{array}$ & $78.9 \pm 1.3$ & $66.5 \pm 1.6$ & $<0.001$ & $76.3 \pm 1.3$ & $66.5 \pm 1.5$ & $<0.001$ & 0.169 & 0.990 \\
\hline $\begin{array}{l}\text { Places where they had seen someone } \\
\text { smoking, mean }\end{array}$ & $2.03 \pm 0.06$ & $1.36 \pm 0.05$ & $<0.001$ & $2.07 \pm 0.06$ & $1.42 \pm 0.05$ & $<0.001$ & 0.596 & 0.423 \\
\hline \multicolumn{9}{|l|}{ SHS per day among non-smokers (\%) } \\
\hline $0 \mathrm{~min}$ & $47.2 \pm 1.9$ & $56.0 \pm 1.9$ & $<0.001$ & $49.6 \pm 1.8$ & $65.5 \pm 1.7$ & $<0.001$ & 0.568 & 0.001 \\
\hline $1-20 \min$ & $36.4 \pm 1.8$ & $33.6 \pm 1.8$ & & $33.3 \pm 1.7$ & $24.4 \pm 1.5$ & & & \\
\hline $21-60 \mathrm{~min}$ & $9.1 \pm 1.1$ & $6.8 \pm 1.0$ & & $9.4 \pm 1.0$ & $6.8 \pm 0.9$ & & & \\
\hline$>60 \mathrm{~min}$ & $7.3 \pm 1.0$ & $3.6 \pm 0.7$ & & $7.8 \pm 0.9$ & $3.3 \pm 0.6$ & & & \\
\hline
\end{tabular}

${ }^{*}$ Results were presented as mean \pm SE or percentage \pm SE.

tStatistical tests for differences between intervention and comparison areas in the baseline (or follow-up) survey.

¥Statistical tests for before-after differences in the intervention (or comparison) areas.

FV, fruit and vegetable; IPAQ, International Physical Activity Questionnaires; MET, metabolic equivalent of physical activity; SHS, secondhand smoke. 
places in which people observed smoking decreased in the intervention and comparison areas. Non-smokers' exposure to SHS in the intervention and comparison areas declined during the follow-up.

\section{DISCUSSION}

This is the first comprehensive CBI programme with rigid evaluation in urban China, which was based on the best available evidence on intervention practices and addressed knowledge, attitudes and behaviour with respect to three major lifestyle issues in a general population. After the implementation of a 2-year multilevel intervention in four settings, beneficial changes were noted in smoking and PA, but not in diet, in the intervention areas compared with the comparison area.

It has been proved that smoking bans and restrictions reduce exposure to $\mathrm{SHS}^{19}$ and tobacco use among workers when these restrictions are implemented in worksites or by communities. ${ }^{20}$ A Smoke Control Ordinance in Public Places of Hangzhou officially took effect on 1 March 2010. This ordinance prohibits smoking in 10 types of public places and limits smoking in nine types of public places. Our study demonstrated a statistically significant improvement in tobacco-related knowledge and beliefs and a decrease in exposure to SHS for the intervention and comparison areas and a $25.8 \%$ decline in the current smoking prevalence for the intervention areas after a 1-year implementation of a city-wide smoking ban. The national standardised prevalence of smoking among adults between the ages of 15 years and 69 years in China demonstrated a slight improvement, from $28.5 \%$ in 2002 to $27.9 \%$ in $2010 . .^{21}$ Compared with national trends, the introduction of smoke-free legislation appears to be effective in this city. The legislation is city-wide, but only the intervention areas exhibited a decline in the prevalence of smoking. One possible explanation is that antismoking legislation was incorporated into a multicomponent community and workplace intervention in the intervention areas, which was more effective than the strictly legislation-based approach that occurred in the comparison area. A relatively low level of smoking prevalence may also explain the lack of a significant decrease in smoking in the comparison area. However, the reduction in the smoking prevalence among men in the intervention areas was quite large over just a 2-year period. Another possible explanation is that less nicotine-dependent smokers tend to change their behaviours responding to tobacco cessation interventions, and thus, more dependent smokers are likely to remain in a population with lower smoking prevalence. The difference in before-after changes between intervention and comparison areas may be partly explained by the difference in the proportion of less nicotine-dependent smokers. More analyses and continued monitoring of population-level smoking are needed to address this issue.

Three categories of intervention that have been proven to be effective in promoting levels of $\mathrm{PA}^{22}$ were involved in this programme, including point-of-decision prompts to encourage the use of stairs, environmental interventions targeting the built environment and mass media campaigns. This combined approach may partially explain the positive change in PA noted in our study. However, integrated CBI programmes are comprehensive packages in which different types of feasible activities are combined to produce a synergistic effect. ${ }^{5}$ Thus, we may not be able to identify the effect of each component. Environmental and policy approaches are often difficult and require a longer time to implement than informational approaches. Hangzhou was experiencing enormous changes, including the initiation of a public bicycle service system on 1 May 2008 and the construction of walking trails with stone distance markers. This situation provided us an opportunity to evaluate the short-term impact of these environmental changes on individual PA. The public bicycle service system covers the entire city. However, a higher proportion of subjects in the intervention areas than in the comparison area reported having ridden public bicycles. Higher socioeconomic status and higher car ownership in the comparison area may explain this area's lower use of public bicycles. The promotion of walking and cycling as part of transport may be more effective for lower socioeconomic groups than for more affluent populations. ${ }^{23}$ A before-after mean difference of 182 MET-min/week in the intervention areas might be translated to an increase of $6.5 \mathrm{~min}$ of moderate PA per person per day. Small as they are, moderate and achievable change by the population as a whole might greatly reduce the number of people with conspicuous problems. ${ }^{24}$

The informational and educational approaches were used as the main strategies on our dietary interventions. Unfortunately, no positive change in FV consumption could be attributed to our intervention efforts. Modern lifestyle and time restrictions have contributed to a significant increase in food consumption away from home $\mathrm{e}^{25-27}$ and an increasing dependence on commercial packaged foods. However, foods cooked at restaurants and commercially packaged foods are outside of individuals' control. To reach large general populations and to achieve and sustain the adoption of healthy eating across the population, policy and environmental strategies are required, which has not been achieved in our short intervention period. In addition, food safety issues have received high-level public and political attention in China. ${ }^{28}$ Concerns about food safety overwhelm concerns about healthy food.

We acknowledge the limitations of this programme. First, theoretically, the comparison area should be sufficiently geographically distant from the intervention areas to minimise contamination of the intervention. However, the districts and counties in Hangzhou that were located farther away from the intervention areas were less similar to the intervention areas with respect to urban development. Therefore, this selection of study areas that was in close geographic proximity increased the possibility of contamination between the intervention and comparison areas. Furthermore, it is politically difficult to persuade the local government to agree to avoid engaging in any prevention activities during the course of the study. ${ }^{29}$ The comparison area was allowed to follow routine practices for NCD prevention and control.

Second, the intervention and comparison areas were different in some population characteristics. It is difficult to achieve good comparable basic characteristics between intervention and comparison groups with less number of communities. Our study units were established at the district level. Few districts in the same city were available for this project. This limitation increases the complexity in explaining our results. Thus we aimed to present the changes of different characteristics of districts having experienced different intervention activities in this article.

Third, one of the most difficult aspects of community-level programmes is ensuring sufficient penetration throughout a community to attain a population-level impact. ${ }^{30}$ In our study, no single intervention activity was reported by more than half of the subjects. The difficulty of engaging large proportions of a population in interventions may prevent an impact beyond the secular trend towards improvement. All of the aforementioned issues may reduce the apparent intervention effects of the programme. Despite these limitations, we identified beneficial effects favouring the intervention areas in smoking and PA. 
The CIH programme did not use a standardised intervention protocol. The interventions were chosen to match local needs and capabilities. Interventions that are culturally, environmentally and socially appropriate are far more likely to be implemented and sustained. The implementation of interventions was based on the existing local system for the prevention and control of NCDs instead of a one-off recruitment of programme staff. All of the programme-specific interventions were integrated into local routine practices in NCD prevention and control. We did not pursue the highest intervention intensity but rather an appropriate intensity at which the intervention activities could be sustained with the existing local resources and workforce after the completion of this programme's funding.

\section{What is already known on this subject}

Although there is sufficient knowledge about 'what should be done' to address the leading non-communicable diseases (NCDs) and their underlying risk factors, the key question at present is how can our existing knowledge of NCDs be best applied to effective prevention in real-life situations in different social and cultural environments and their particular political and organisational systems?

\section{What this study adds}

- A community-based multilevel intervention programme is feasible in urban China.

- After a 2-year intervention, beneficial changes were noted in the intervention areas with respect to smoking and physical activity but not diet.

Acknowledgements The authors are deeply indebted to the study participants for their participation and to all the staff in the districts of Xiacheng, Gongshu and Xihu in Hangzhou for their efforts that made the study possible.

Collaborators Community Interventions for Health $(\mathrm{ClH})$ collaboration.

Contributors $J \mathrm{~L}$ developed evaluation designs and intervention activities of Hangzhou, and drafted the manuscript. QML and YJR organised the field work and implemented part of intervention activities. PPH undertook the statistical analysis. SFW implemented sampling procedure and part of intervention activities. FG organised data entry and part of statistical analysis. LML developed whole research designs, contributed to the interpretation of the results and reviewed the manuscript. All authors read and approved the final manuscript.

Funding Community Interventions for Health $(\mathrm{CIH})$ is supported by a registered UK charity, the Oxford Health Alliance (OxHA), and facilitated by MATRIX Public Health Solutions. For a full list of donors supporting OxHA please go to http://www.oxha.org.

\section{Competing interests None.}

Ethics approval The study was approved by the Institutional Review Board at Peking University Health Science Center (IRB00001052-08003).

Provenance and peer review Not commissioned; externally peer reviewed.

Open Access This is an Open Access article distributed in accordance with the Creative Commons Attribution Non Commercial (CC BY-NC 3.0) license, which permits others to distribute, remix, adapt, build upon this work non-commercially, and license their derivative works on different terms, provided the original work is properly cited and the use is non-commercial. See: http://creativecommons.org/ licenses/by-nc/3.0/

\section{REFERENCES}

1 World Health Organization. Global status report on noncommunicable diseases 2010. Geneva: World Health Organization, 2011.
2 World Bank. Toward a healthy and harmonious life in China: stemming the rising tide of non-communicable diseases 2011. http://www.worldbank.org/content/dam/ Worldbank/document/NCD report en.pdf (accessed 8 Sep 2013).

3 Yang G, Kong L, Zhao W, et al. Emergence of chronic non-communicable diseases in China. Lancet 2008;372:1697-705.

4 Puska P, Vartiainen E. Community-based intervention studies in high-income countries. In: Detels R, Beaglehole R, Lansang M, Gulliford M, eds. Oxford Textbook of Public Health. Oxford: Oxford University Press, 2009.

5 Nissinen A, Berrios X, Puska P. Community-based noncommunicable disease interventions: lessons from developed countries for developing ones. Bull World Health Organ 2001;79:963-70.

6 McLeroy KR, Bibeau D, Steckler A, et al. An ecological perspective on health promotion programs. Health Educ Q 1988;15:351-77.

7 Stokols D. Translating social ecological theory into guidelines for community health promotion. Am J Health Promot 1996; 10:282-98.

8 Richard L, Potvin L, Kishchuk N, et al. Assessment of the Integration of the ecological approach in health promotion programs. Am J Health Promot 1996:10:318-28.

9 Glanz K, National Cancer Institute. Theory at a glance: a guide for health promotion practice, 2005. http://www.cancer.gov/PDF/ 481f5d53-63df-41bc-bfaf-5aa48ee1da4d/TAAG3.pdf (accessed 29 Oct 2013).

10 Mercer SL, DeVinney BJ, Fine LJ, et al. Study designs for effectiveness and translation research: identifying trade-offs. Am J Prev Med 2007;33:139-54

11 Baker PRA, Francis DP, Soares J, et al. Community wide interventions for increasing physical activity. Cochrane Database Syst Rev 2011;(4):CD008366.

12 NHS National Institute for Health and Clinical Excellence. Physical activity and the environment: NICE public health guidance 8, 2008. http://www.nice.org.uk/ nicemedia/live/11917/38983/38983.pdf (accessed 29 Oct 2013).

13 Duffany KO, Finegood DT, Matthews D, et al. Community Interventions for Health $(\mathrm{CIH})$ : a novel approach to tackling the worldwide epidemic of chronic diseases. CVD Prev Control 2011;6:47-56.

14 Lv J, Liu QM, Ren YJ, et al. Socio-demographic association of multiple modifiable lifestyle risk factors and their clustering in a representative urban population of adults: a cross-sectional study in Hangzhou, China. Int J Behav Nutr Phys Act 2011;8:40.

15 World Health Organization. The WHO STEPS surveillance manual-WHO STEPwise approach to chronic disease risk-factor surveillance. http://www.who.int/chp/steps/ manual/en/index.html (accessed Oct 2013).

16 Craig CL, Marshall AL, Sjöström M, et al. International physical activity questionnaire: 12-country reliability and validity. Med Sci Sports Exerc 2003;35:1381-95.

17 IPAQ Core Group. Guidelines for the data processing and analysis of the International Physical Activity Questionnaire-short and long forms. http://www. ipaq.ki.se/scoring.pdf (accessed 8 Sep 2013).

18 StataCorp. Stata Statistical Software: Release 12.1 [program]. College Station, TX: StataCorp LP, 2011.

19 Hopkins DP, Briss PA, Ricard CJ, et al. Reviews of evidence regarding interventions to reduce tobacco use and exposure to environmental tobacco smoke. Am J Prev Med 2001;20:16-66.

20 Hopkins DP, Razi S, Leeks KD, et al. Smokefree policies to reduce tobacco use. A systematic review. Am J Prev Med 2010;38:S275-89.

21 Chinese Center for Disease Control and Prevention. Global Adult Tobacco Survey (GATS) China 2010 country report. Beijing: China Three-Gorge Publishing House, 2011.

22 World Health Organization. Interventions on diet and physical activity: what works. Geneva: World Health Organization, 2009.

23 Bloomberg MR. Active design guidelines: promoting physical activity and health in design, 2011. http://www.nyc.gov/html/ddc/html/design/active_design.shtml (accessed 8 Sep 2013).

24 Rose G, Khaw KT, Marmot M. Rose's strategy of preventive medicine. New York: Oxford University Press, 2008

25 Bes-Rastrollo M, Basterra-Gortari FJ, Sanchez-Villegas A, et al. A prospective study of eating away-from-home meals and weight gain in a Mediterranean population: the SUN (Seguimiento Universidad de Navarra) cohort. Public Health Nutr 2010;13:1356-63.

26 Guthrie JF, Lin BH, Frazao E. Role of food prepared away from home in the American diet, 1977-78 versus 1994-96: changes and consequences. J Nutr Educ Behav 2002;34:140-50.

27 Orfanos P, Naska A, Trichopoulos D, et al. Eating out of home and its correlates in 10 European countries. The European Prospective Investigation into Cancer and Nutrition (EPIC) study. Public Health Nutr 2007;10:1515-25.

28 Editorial. Food safety in China: a long way to go. Lancet 2012;380:75.

29 Sanson-Fisher RW, Bonevski B, Green LW, et al. Limitations of the randomized controlled trial in evaluating population-based health interventions. Am J Prev Med 2007;33:155-61.

30 Merzel C, D'Afflitti J. Reconsidering community-based health promotion: promise, performance, and potential. Am J Public Health 2003;93:557-74. 